\title{
Go West, In The Open Air: Parada do Orgulho LGBT Goianiense - da repressão à turistificação*
}

\author{
Go West, In The Open Air: LGBT Pride Parade Goianiense - from the repression \\ to the touristification
}

\section{Carlos Eduardo Santos Maia}

Universidade Federal de Juiz de Fora - Brasil

carlmaia@uol.com.br

\section{Resumo}

A parada LGBT goianiense, cuja $17^{\mathrm{a}}$ edição ocorreu no ano de 2013, é o tema deste artigo. Através de uma geografia histórica das mudanças nas suas territorialidades, procuramos expor como a parada se realizou no final do século XX por um grupo de menos de 10 militantes celebrando o "mito de Stonewall Inn' de modo ocultado pela cena pública e reprimido pelo poder público, mas chega ao início do século XXI como uma festa que atrai participantes do entorno de Goiânia, e mesmo de áreas mais distantes, com temas afinados à realidade social brasileira vivenciada pelos cidadãos LGBTs, especialmente a busca dos mesmos direitos civis garantidos aos heterossexuais e a criminalização da homofobia. Metodologicamente, utilizamos pesquisa bibliográfica, documental e de campo em que operam como base analítica os conceitos de territorialidade, homonacionalismo, homofobia, ritual, entre outros.

Palavras-Chave: Parada LGBT; Goiânia; Territorialidade; Homonacionalismo; Ritual.

\begin{abstract}
The subject of this article is the LGBT parade in the city of Goiânia, whose 17th edition took place in 2013. Through a historical geography of the changes in their territorialities, we seek to expose how the parade had been carried out by less than 10 activists at the end of the 20th century, celebrating the 'Stonewall Inn myth' "hidden" from the public at large and "repressed" by the authorities. On the other hand, the celebration at the beginning of the 21th century attracted participants from the Goiânia surroundings and even from distant regions. The theme was related to the LGBT citizens who demand the same civil rights enjoyed by heterosexuals and fight for the criminalization of homophobia in Brazil. The methodology was based on a bibliographic, documental and field research under the concepts of territoriality, homonationalism, homophobia and rituals, amongst others.
\end{abstract}

Keywords: LGBT Parade; Goiânia; Territoriality; Homonationalism, Ritual. 


\section{Come on, come on...}

Temos assistido, na mídia, um caloroso debate envolvendo o direito das minorias intituladas LGBTs, especialmente no que diz respeito à conquista dos mesmos direitos garantidos aos heterossexuais e ao combate e à criminalização da homofobia, tanto no Brasil como em outros estados democráticos. Reações a isso, por outro lado, também são noticiadas, inclusive em países que primaram por ideais de democracia; ressalte-se aqui, por exemplo, a França e seus princípios de liberté, egalité et fraternité que parecem colocados em xeque por parcela retrógrada da sua sociedade avessa ao 'casamento gay', a qual ocupou as ruas de Paris, no ano de 2013, em duas grandes manifestações, uma aos 13 de janeiro (contando com cerca de 340.000 participantes) e outra no dia 24 de março (havendo aproximadamente 300.000 integrantes).

Afora a questão da justiça social e dos direitos civis trazidos à baila pelo movimento LGBT, não se pode relegar os atentados homofóbicos que descambam em violência física, psicológica e verbal, ou mesmo em assassinatos. No Brasil, facções religiosas, principalmente de viés neopentecostal, colaboram para acirrar - e legitimar - a ideologia da negação dos direitos LGBTs, ratificando as duas 'raízes profundas' para a homofobia que Spencer (1998, p. 460) destaca:

Il semble possible que l'homosexualité soit psychologiquement choquante pour certains car elle paraît atteindre la survie même de notre espèce (...) La peur de l'acte homosexuel englobe donc aussi la peur du paganisme, la peur que les barbares soient à nos portes; ce type de langage est (...) souvent employé par les prêtres et

\section{les auteurs courroucés'.}

Para estas facções, o sufixo fobia, no que se refere ao vocábulo homofobia, denota, como observa Goetzmann (2001, p. 71) ao referir-se a este termo, um "sens de rejet, voire de condamnation. L'homosexualité est désignée comme une pratique perverse, anormale, contre nature". Estas concepções da homossexualidade como anormalidade e aberração fazem-se acompanhar de discursos 'hetero-nômicos' sobre as formas de prazer, que são encaixotadas em padrões determinados e preconceituosos do que é moral, legal e normalmente aceito, conforme as palavras do controverso pastor Marco Feliciano, ocupante da Presidência da Comissão de Direitos Humanos da Câmara dos Deputados, em entrevista concedida à Revista Veja: "união homossexual não é normal. $O$ reto não foi feito para ser penetrado" (BORGES, 2013).

Neste trabalho, discutiremos as paradas LGBTs como manifestações festivas que trazem à cena pública reivindicações e problemas enfrentados por estas 'minorias', enfatizando a dinâmica territorial $\mathrm{e}$ as territorialidades que perpassam a parada goianiense ao longo de sua historicidade: de um movimento oculto e pontual a um evento regional, midiático e turistificado. $\mathrm{O}$ trabalho apoia-se em discussões teóricas e resgate de uma geografia histórica baseadas em levantamento bibliográfico e em análises respaldadas em notícias de jornais do caso goianiense, recorrendo-se ainda a entrevistas realizadas com participantes e organizadores do evento.

Together, We will go our way 
Reconhece-se comumente como a primeira parada do orgulho LGBT aquela realizada em Nova Iorque, aos 28 de junho de 1970, que tinha como palavra de ordem Come out!, celebrando a rebelião ocorrida um ano antes em Stonewall Inn, "un bar appartenant à la Mafia new-yorkaise, situé dans Christopher Street, une rue de Greenwich Village, est très couru par les homosexuels blancs de la classe moyenne" (LEROY, 2010, p. 3). Esta rebelião, que promoveu conflitos entre policiais e frequentadores do bar apoiados por negros, hippies e outras minorias reunidas em ambientes próximos ao Stonewall Inn, colocou em pauta a necessidade de um ativismo homossexual que valorizasse a visibilidade, e não o ocultamento (BRANSON, s.d.; LEROY, 2010); substituindo-se o próprio termo homossexual, carregado de sentido médico-patológico, pela positividade e 'masculinidade' da palavra gay (GRAU, 2000 e 2010), denotando um significado social e um modo de vida traduzido no orgulho (GOETZMANN, 2001).

Destarte, a resistência à repressão policial em Stonewall Inn é o 'mito fundador' das Paradas Gays (e veremos que este mito é o leimotiv do orgulho manifesto nas primeiras paradas goianienses), mas a militância homossexual antecede este evento. $\mathrm{O}$ que a parada nova-iorquina inaugura é a ida da militância para as ruas dando ênfase ao 'orgulho público' - the gay pride (BROQUA in PRADO, 2000; BLIDON, 2009), conforme os próprios organizadores da marcha propuseram, segundo as considerações de Sargeant (2010, s/p):

One year after the Stonewall Riots galvanized New York's fearful gay men and lesbians into fighters, a handful of us planned our first march. We had no idea how it would turn out. We weren't even certain we would be granted a permit. And now, here we were, June 28, 1970, with people gathered west of Sixth Avenue at Waverly Place. We wondered if we would be able to get them to move off the curb...

Finally, we began to move up Sixth Avenue. I stayed at the head of the march the entire way, and at one point, I climbed onto the base of a light pole and looked back. I was astonished; we stretched out as far as I could see, thousands of us. There were no floats, no music, no boys in briefs. The cops turned their backs on us to convey their disdain, but the masses of people kept carrying signs and banners, chanting and waving to surprised onlookers...

After months of planning and internal controversy, the Christopher Street Liberation Day Umbrella Committee negotiated with more than a dozen very different gay organizations. One of the largest hurdles was which group would have the honor of heading the march. It was only when Craig and Michael Brown, who'd arranged for those first permits, decided that each group would have one representative was the matter finally settled. Even the question of a chant was endlessly discussed - the winner: 'Say it clear, say it loud. Gay is good, gay is proud.'

Como assinala Blidon (2009, p. 3), "le phénomène ne connaît pas immédiatement un succès mondial. La première marche organisée à San Francisco l'est deux ans plus tard, en 1972; San Francisco, comme d'autres villes américaines, revendiquant des 
émeutes antérieures". Na Europa, as paradas tendo como mito fundador a rebelião de Stonewall Inn e como leimotiv o 'orgulho' chegaram ainda nos anos 70 , em 1972 ou $1973^{1}$ na cidade de Londres e, em 1979, nas cidades de Berlim e Paris.

No Brasil, em função do contexto político ditatorial e do avanço da AIDS, que era pejorativamente chamada de câncer ou peste gay, as paradas LGBTs ocorreram a partir de meados dos anos 90, quando também foi criada a Associação Brasileira de Gays, Lésbicas e Transgêneros - ABGLT, aos 31 de janeiro de 1995. O apoio do Ministério da Saúde às ONGs voltadas à prevenção das DSTs, especialmente a AIDS, foi fundamental na articulação da militância e na preparação de manifestações públicas como a parada.

De acordo Nascimento (s.d.), a primeira marcha no Brasil foi realizada aos 25 de junho de 1995, no Rio de Janeiro, contando com pouco mais de 3.000 integrantes. "No ano seguinte, em 1996, o Rio lançou a Primeira Parada do Orgulho Gay, em Copacabana. São Paulo só realiza a sua primeira Parada um ano depois" (CONDEIXA, 2009, p. 12). A parada de maior notoriedade em solo brasileiro, quanto à concorrência de público, é a de São Paulo; mas em sua primeira edição, realizada aos 28 de junho de 1997, houve cerca de 2.000 participantes (SANTOS, 2007). O recorde de público do evento deu-se nas edições de 2007 e 2010, com cerca de 3,5 milhões de pessoas.

\section{Together, We will make our plan}

A geografia histórica da parada goianiense foi difícil de resgatar, mesmo sendo um evento recente. Tivemos que preencher hiatos documentais pelo confronto das fontes disponíveis (que não são muitas) e o recurso a outras fontes de pesquisa, tal como a memória dos participantes, também se mostrou problemático, pois esta é bastante seletiva e tendenciosa nas informações armazenadas. Assim, procuramos dar uma versão à constituição geo-historial da parada LGBT de Goiânia, particularmente no que diz respeito às alterações em sua territorialidade, pois esta deixou de ser uma manifestação estritamente política de militantes LGBTs ocupando uma área pontual para realizar-se como festa em deslocamento pelas principais avenidas do Centro da cidade, inclusive com caráter político, mas não 'só isso' - pois a festa é um fato social total (MAIA, 2010a).

$\mathrm{O}$ primeiro evento considerado pelos organizadores como 'parada' ocorreu aos 28 de junho de 1996, rememorando Stonewall. Nesta data, o jornal O Popular, noticiava Movimento GLS Comemora Dia de Orgulho Gay, divulgando o acontecimento de um ato às 10 horas, no Monumento das Três Raças, e de uma quadrilha Gay, no Castelinho, situado no Lago das Rosas, às 21 horas. Na mesma matéria, atribuía-se o evento à Associação Ipê Rosa que, segundo informava seu presidente ao referido jornal, contava com cerca de 30 associados. A reportagem ainda mencionava o poder de consumo dos gays $(\mathrm{O}$ POPULAR, 28/6/1996, p. 2).

Segundo depoimento que obtivemos de um dos organizadores eram " 9 manifestantes e 20 policiais". As fotos disponíveis nos mostram faixa de protesto à frente do Monumento às Três Raças e um participante empunhando uma bandeira negra com triângulo rosa invertido (modo como os nazistas marcavam os homossexuais). Esta se materializou num abraço ao Monumento, situado na Praça Cívica, centro político da cidade, e na tentativa dos participantes do ato de colocarem perucas e roupas femininas nas estátuas (de três homens representando o branco, o negro e o índio), o que foi reprimido pela polícia. Destarte, na microterritorialidade temporária deste evento, a 
confluência interescalar do macro e do micro se faz presente, bem como o confronto entre progressismo e conservadorismo, tanto quanto traduções da recusa em ser recusado (FORTUNA, 2012).

Conforme se divulgou na época, a repressão policial já era esperada e, politicamente, talvez fosse intenção induzi-la a fim de expor o conservadorismo da sociedade goianiense:

De acordo com o comandante de Guarda do Palácio das Esmeraldas (...) o ato foi reprimido porque o monumento é um bem público e não pode ser descaracterizado. "Eles têm toda liberdade de se pintarem e colocarem perucas, mas não podem fazer isso com as estátuas", disse.

A intenção do Grupo Gay Ipê Rosa, que organizou a manifestação, era mostrar que os homossexuais também foram responsáveis pela construção de Goiânia, disse o presidente do grupo... (DIÁRIO DA MANHÃ, 29/6/1996, p. 2)

Um ato de protesto irreverente $\mathrm{e}$ bem humorado dos homossexuais foi reprimido pela polícia e segurança do Palácio das Esmeraldas (...) İntegrantes da Associação İpê Rosa realizaram a primeira manifestação GLS (...), em Goiás, no Dia Mundial do Orgulho Homossexual. Mas não puderam vestir as estátuas do índio, branco e negro (...) com roupas GLS - saias de tule, cetim e perucas.

A polícia apreendeu as fantasias num gesto interpretado como violência psicológica pelo presidente da İpê Rosa (...) "Aconteceu o que prevíamos", observou o pastor evangélico assumidamente homossexual.

O sargento Mello, da segurança do Palácio das Esmeraldas, explicou que a ordem partiu do Gabinete Militar sob a alegação de que o monumento é um patrimônio público e não privado de alguns grupos. $\mathrm{O}$ sargento só não soube explicar por que a polícia não interviu com esse argumento quando o artista plástico Leo Pincel vestiu as estátuas com fraldas em protesto contra a proibição do nu artístico nas aulas da Fundação Pedro Ludovico (...), em maio de 1995.

O representante dos GLS argumentou que a praça é do povo que paga impostos e que não havia a intenção de sujar ou mutilar o monumento. Depois de uma rápida conversa, as vestimentas foram liberadas pela polícia para os manifestantes vestirem e posarem para fotos junto com a bandeira do movimento com um triângulo cor de rosa.

Apenas 8 homossexuais masculinos participaram da manifestação $(\mathrm{O}$ POPULAR, 29/6/1996, p. 2)

No ano seguinte, não houve nenhum ato, mas o Diário da Manhã (29/6/1997) divulgou a realização da Mostra de Cinema Gay, em São Paulo, promovida pelo grupo Pela Vidda. Todavia, em 1998, ano da segunda manifestação, as notícias já corriam às vésperas: 
Amanhã rola o Dia do Arco-íris. Cantores bolivianos e goianos vão dar as caras. O babado fortíssimo é esquema do grupo Ipê Rosa. Que luta pelos direitos dos gays, lésbicas e simpatizantes. O local não podia ser mais apropriado: o Bosque dos Buritis. E começa às cinco da tarde (DIÁRIO DA MANHÃ, 27/6/1998, p. 8)

Ainda aos 27/6/1998, o Diário da Manhã publicava uma matéria sobre a eleição de 'Miss Travesti' ocorrida dois dias antes numa boate GLS da cidade. Já no dia 28 de junho, este veículo publicava:

Pela primeira vez em Goiânia, gays, lésbicas, travestis, negros, jovens e mulheres se unem para protestar por dignidade. $\mathrm{O}$ encontro comemora o Dia da Diversidade Humana, e acontece hoje, às 17 horas, no Bosque dos Buritis.

A inspiração vem da comemoração do Dia do Orgulho Gay, celebrado no mundo inteiro depois que no dia 28 de junho de 1968 (sic) alguns homossexuais que estavam no Stonewall Bar [sic], nos Estados Unidos, entraram em confronto com a polícia por não admitir mais as constantes humilhações (DIÁRIO DA MANHÃ, 28/06/1998, p. 3)

Paralelamente, O Popular, nas Cartas dos Leitores (28/6/1998, p. 11), publicou um texto do decano do Movimento Gay no Brasil, Luiz Mott, no qual, entre outros aspectos, Mott chama atenção para os assassinatos motivados por homofobia e a necessidade de se defender a cidadania LGBT. Nesta mesma edição, uma matéria intitulada Homossexuais Comemoram Hoje o Dia da Diversidade ocupava uma página completa, mas sem que houvesse qualquer chamada na primeira página de $\mathrm{O}$ Popular, que tinha como manchete o resultado positivo da seleção brasileira frente ao Chile na copa do mundo, além dos resumos de outros noticiários que compunham aquela edição (político-partidários, fofocas de TV, econômicos, etc., mas sequer uma linha mencionando a página 13 inteira e a reportagem sobre o Dia da Diversidade). Neste sentido, os jornais nos permitem fazer uma leitura das territorialidades humanas pela própria maneira que ostentam ou dissimulam o que está sendo noticiado, ou seja, as espacialidades das notícias nas suas próprias páginas desvelam quais são as tendências de poder hegemônicas ou subalternas e as tensões do que se pode divulgar e como se divulgam as negociações entre estas tendências.

Retornando à referida notícia, entre os temas abordados observava-se a origem do orgulho gay, sua difusão no Brasil, os conflitos familiares envolvendo gays, lésbicas e travestis e advertia-se que o 'homossexualismo', termo em desuso atualmente, não era considerado doença pela Organização Mundial de Saúde e, mesmo no Brasil, desde 1995, o Conselho Federal de Medicina o retirara da lista de desvios sexuais, aproveitando-se para especular sobre as suas possíveis causas. Acerca da manifestação, divulgou-se que uma "comemoração (...) mais ampla. Em vez de celebrar o Dia do Orgulho Gay, os homossexuais preferiram pedir apoio a outras minorias e, em conjunto, fazer um ato cultural em defesa da diversidade humana" (O POPULAR, 28/6/1998, p. 13). Na matéria, assinalava-se que o ato também seria 'festivo', tendo como palco o Bosque dos Buritis. A estratégia, segundo depoimento de um dos organizadores ao jornal O Popular, era dar maior visibilidade e sair do gueto. Mencionavam-se ainda as associações LGBT existentes em Goiás (Ipê Rosa, AGLT e 
Grupo Pista) e as motivações de sua existência: contaminação pelo vírus da AİDS e defesa da cidadania e dos direitos civis. Outro ponto abordado era $\mathrm{o}$ direito à privacidade, acerca do que um dos depoentes exarava: "Nós achamos importante dar visibilidade à causa gay, mas ninguém tem o direito de perguntar se uma pessoa é ou não homossexual" (O POPULAR, 28/6/1998, p. 13). Nota-se nesta, segunda edição do evento, conforme destaca Di Méo (2001, p. 112), que "la fête inscrit ensuite le territoire local dans divers registres de références et d'échelles géographiques".

As notícias do dia seguinte à comemoração relatavam a "cara diferente" do Bosque dos Buritis em virtude da manifestação, que aliou vários segmentos, chamando a atenção para o fato de que "gays e heteros se reuniram (...) para cobrar uma sociedade sem preconceitos" (DIÁRIO DA MANHÃ, 29/06/1998, p. 3).

Em 1999, outro ato foi realizado no Bosque dos Buritis, instigando seus frequentadores, conforme inferimos por arquivo fotográfico ${ }^{2}$, no qual nota-se a presença de integrante fantasiado. No jornal O Popular (28/6/1999) divulgou-se a realização da Terceira Parada do Orgulho Gay em São Paulo, sendo ainda publicada no dia 30/6/1999 uma entrevista com o antropólogo Luiz Mott acerca de seu livro Homossexuais da Bahia - Dicionário Biográfico. A Parada de São Paulo foi ainda noticiada no Diário da Manhã, que também divulgou o aumento da violência contra lésbicas goianas, de acordo com pesquisa feita pelo Grupo de Lésbicas de Goiás e pela Associação Goiana de Gays, Lésbicas e Travestis (28/6/1999). Não encontramos nada em O Popular e tampouco no Diário da Manhã sobre a 'parada' goianiense de 1999.

No ano seguinte, os manifestantes, liderados pela Associação Ipê Rosa ${ }^{3}$, ocuparam o trecho da Rua 8, no Centro, conhecido como Rua do Lazer, sendo concedida permissão pela Secretaria Municipal de Desenvolvimento Econômico para realizarem "Encontro Cultural" no dia 28 de junho, das 17 às 19 horas. Nesta data, O Popular publicou uma reportagem bem destacada sobre o avanço da Aids no mundo $(28 / 6 / 2000$, p. 13) e uma nota sobre o assassinato de uma travesti na cidade $(28 / 6 / 2000$, p. 6B). O curioso é que no dia 26 de junho, na capa do jornal, havia chamada para uma matéria publicada em sua página 15 (folha quase inteira, com direito a fotos coloridas) sobre a participação de goianos na parada gay de San Francisco (EUA). Nesta mesma folha, havia um rápido texto sobre a $4^{\text {a }}$ Parada de São Paulo. Assim no final do milênio, paradas alhures chamaram mais atenção que 'aquela dali' na mídia impressa e colocavam um modelo de evento que logo seria adotado pela organização goianiense: desfile pelas ruas com pessoas fantasiadas e tônica festiva, inclusive dada pela música eletrônica, atraindo participantes e espectadores.

No ano de 2001, também aos 28 de junho, o Dia Mundial do Orgulho Gay voltou a ser comemorado na 'Rua do Lazer'. Neste alvorecer do século XXI, notamos nas fotos disponíveis existência de decoração do local com bolas coloridas, alguns elementos fantasiados, travestis e a bandeira do arcoíris. De acordo com O Popular, houve três estandes com cartazes e distribuição de folhetos explicativos sobre prevenção da AIDS e de serviços criados para combater a discriminação por orientação sexual. A edição de 2001, particularmente, teve ampla cobertura do Diário da Manhã e de O Popular, com reportagens nos dias 28 e 29 de junho enfatizando o 'mito de Stonewall'. Isto ratifica a asseveração de DI MÉO (2001, p. 48) de que "la fête, justement, contribue à territorialiser les lieux. Mais plus encore 
qu'une géographie concrète, la fête engendre et décrit une géographie symbolique. L'espace concerné y revêt une dimension mythique, celle de quelques passages essentiels pour les sociétés". Em matéria publicada no dia 28 , entre outros aspectos, destacava-se o caráter festivo do evento celebrante do 'mito':

A Parada Gay tem o apoio de diversas entidades (...) O movimento deste ano - o quinto realizado em Goiânia - simula uma festa junina. Além das bandeirolas coloridas, várias barracas serão montadas no calçadão para vender comidas típicas, distribuir panfletos, divulgar informação e entregar preservativos. A novidade deste ano é a participação de lésbicas na manifestação, que será encerrada com uma grande quadrilha improvisada (DIÁRIO DA MANHÃ, 28/6/2001, p. 11-a).

Já nas reportagens do dia 29 relatavam-se os conflitos dos participantes da parada com religiosos, transeuntes e comerciantes, comentando-se:

Mas nem todos respeitam a causa gay. A Parada sofreu a interferência de uma vigília da Igreja Apostólica Renascer em Cristo. Em resposta e dizendo que as rezas não eram comuns naquele horário, o coordenador geral do Ipê Rosa pediu um minuto de silêncio pela solidariedade, amor e compreensão (DIÁRIO DA MANHÃ, 29/6/2001, p. 9-a).

Estranheza, indignação e perplexidade. Essas foram as reações que a Parada Gay, realizada ontem na Rua 8, no Centro, despertou no público (...) Depois de observar a movimentação por algum tempo, muitos espectadores não pouparam crítica à iniciativa. Um comerciante chegou até a baixar as portas de sua loja durante a apresentação.

"Não dá pra trabalhar no meio desse tumulto. Isso é um absurdo", reclamou Fernando Alves (...) Já (...) Kátia Azevedo (...) considerou a Parada apelativa. "Não concordo com esse tipo de exposição. Esses homens vestem-se de mulher e, ao invés de defender a imagem dos gays, conseguem apenas chocar as pessoas"... (O POPULAR, 28/6/2001, p. 13).

Na matéria de O Popular, mencionava-se que era este tipo de reação que os organizadores buscavam combater, colocando em público a diversidade de orientação sexual, o que foi exemplificado nas palavras de uma transexual entrevistada: "Me sinto linda quando coloco um short de renda vermelho, um sapato de salto alto e um top preto que tenho" (O POPULAR, 28/6/2001, p. 13). Observava-se ainda que participaram no evento cerca de 60 pessoas, embora a entidade promotora, Ipê Rosa, tivesse 350 associados, fato que foi explicado pela própria exibição pública naquela forma de comemoração. A matéria era completada com depoimentos de gays e lésbicas sobre os preconceitos que sofreram em casa, no trabalho, em lugares públicos.

Sobre o ano de 2002, encontramos disponível em acervo do Centro de Documentação e Arquivo (Cidarq) da UFG um folder da VI Parada Gay de Goiânia trazendo informações sobre as atividades desenvolvidas no período de 17 a 29 de junho, com o "ato do orgulho homossexual" programado para o dia 28 às 15 horas, na Rua do Lazer. Nele há ainda texto sobre o 
Dia do Orgulho Gay; além de referências a Stonewall, à bandeira do arco-íris (resumo do seu significado, sendo a imagem de fundo do folder um arco-íris) e ao triângulo rosa. Uma bandeira do arco-íris com 50 metros de comprimento foi doada pelo Governo do Estado aos organizadores, conforme notícias publicadas em O Popular (figura 1) e no Diário da Manhã aos 28/06/2002, na qual se mencionava ainda que a sexta parada seria encerrada com concurso da miss drag queen.

Neste período que se estendeu desde 1996 até 2002 já é bastante sensível a contextualização ritualística da parada e, mais ainda, a agregação daquelas características do ritual que demonstram seu valor político exaradas por Kertzer (2001, p. 18), quais sejam: "o poder de representar grupos políticos; de fornecer legitimidade; de construir solidariedade; e de modelar as percepções da realidade política das pessoas" e , diríamos, de territorializar e demonstrar territorialidades. Simultaneamente, a ritualidade amparava o princípio da existência de um mito fundador, como observa Maia (2010b) ao falar dos mitos e rituais, o qual deveria ser cultivado (cultuado) com a tomada progressiva de espaços públicos com territorialidades caleidoscópicas e seus reflexos de preconceitos e de desejos de liberdade, de intolerâncias e de condescendência, de disposições e de im-posições.

Assim, a globalidade do movimento gay

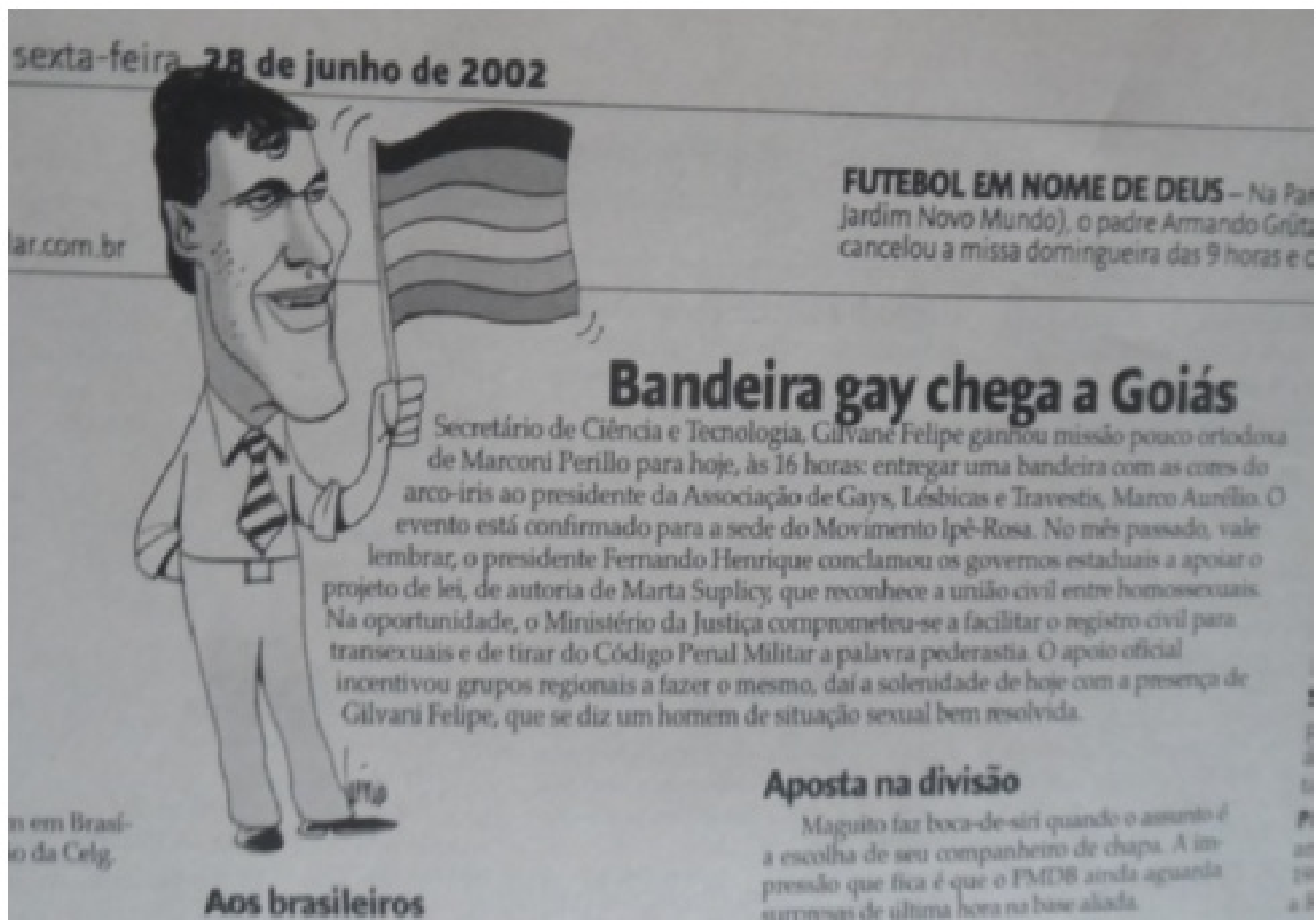

Figura 1: Charge da "chegada da bandeira gay"

Fonte: O Popular, 28/6/2002, p. 9 
em torno de Stonewall como 'mito fundador' tornava premente organizar-se e, mais que isso, organizar para mudar. Mas o que mudou? Queremos neste texto destacar, entre outras mudanças, que a parada perdeu paulatinamente seu caráter de manifestação promovida pontualmente por um grupo de militantes, tornando-se festa circulando pelas ruas centrais com ampla visibilidade (e as suas referências nas primeiras páginas dos jornais pesquisados ratificam isto) para celebrar $\mathrm{o}$ orgulho e, contraditoriamente, desejos de normatividades. Melhor dizendo, a parada goianiense, como outras que aqui ocorrem, acabou por hipotecar apoio a determinadas normatividades (valores religiosos judaico-cristãos expressamente manifestos, ideais de família e união, modelos de comportamento, concepção de 'cultura gay' tomada de empréstimo dos EUA e Europa, etc.), ainda que protestos de 'minorias contra minorias' sejam notados, como no caso os cartazes acerca da passivofobia a serem vistos adiante. Não estaria então a parada a serviço do homonacionalismo, na acepção expressa, a seguir, por Puar (2013, p. 337)

Instead of thinking of homonationalism as an accusation, an identity, a bad politics, I have been thinking about it as an analytic to apprehend state formation and a structure of modernity: as an assemblage of geopolitical and historical forces, neoliberal interests in capitalist accumulation both cultural and material, biopolitical state practices of population control, and affective investments in discourses of freedom, liberation, and rights. Homonationalism, thus, is not simply a synonym for gay racism, or another way to mark how gay and lesbian identities became available to conservative political imaginaries; it is not another identity politics, not another way of distinguishing good queers from bad queers, not an accusation, and not a position. It is rather a facet of modernity and a historical shiftmarked by the entrance of (some) homosexual bodies as worthy of protection by nationstates, a constitutive and fundamental reorientation of the relationship between the state, capitalism, and sexuality.

Vejamos isto melhor a partir do momento que a parada passa a se realizar em circuito pelas ruas e afasta-se da data de 28 de junho, configurando novas territorialidades. $\mathrm{O}$ marco deste novo período é ano de 2003, quando as comemorações estenderam-se de 22 a 29 de Junho, ocorrendo, neste último dia, a Parada Unificada do Orgulho GLBT de Goiânia, com concentração no Bosque Botafogo e término na Praça Universitária. As cores do arco-íris pincelaram o folder de divulgação de modo sensível, notando-se no folheto grande quantidade de entidades organizadoras do evento, que seria encerrado com um show. Esta área de concentração da edição de 2003, o Bosque Botafogo, se tornaria área de concentração e de dispersão da parada goianiense a partir da edição de 2004 até 2010.

O Bosque Botafogo era uma área conhecia pela "pegação" e, durante a parada, vários participantes adentravam no bosque a fim disto (...) Desse modo, a concentração da parada acabava ratificando a centralidade deste point gay de "pegação", além de outro, uma sauna frequentada também por gays que existia em frente ao bosque 
(sauna esta demolida para as obras de reforma do parque) (MAIA, 2012, p. 280).

Aos 28 de junho, O Popular noticiava o concurso Miss Drag Evolution 2003, promovido Ipê Rosa e a AGLT, na rua do lazer, alvissarando que, no dia seguinte, haveria a $1^{\text {a }}$ Parada Unificada do Orgulho GLBT de Goiânia. Notava-se ainda na matéria a ocorrência de uma audiência pública na Câmara Municipal de Goiânia, no dia 27, para tratar de política de direitos humanos voltada aos homossexuais. Fazia-se ainda um convite às famílias goianiense para participarem da parada à exemplo do que ocorrera, na semana anterior, em São Paulo. Finalizando, apresentava-se a programação das atividades dos dias 28 e 29, cujos principais locais de ocorrência seriam a própria rua do lazer (Concurso Miss Drag Evolution), a boate LGBT Oficina Open Club ("festa do orgulho" no dia 28 e "ressaca da parada" no dia 29), o Bosque Botafogo (local de concentração da parada) e a Praça Universitária (local de dispersão e do show de encerramento).

A matéria sobre a parada publicada no Diário da Manhã informava que esta contou com 3.000 participantes, o que concordava com público esperado pelos organizadores do evento em projeto encaminhado à Secretaria Municipal de Cultura $^{1}$, observando seu caráter ritualístico e a participação majoritária de homossexuais:

Cada um com seu estilo, os homossexuais fizeram a festa. Eles literalmente pararam o trânsito por onde passavam. A passeata foi acompanhada de trio elétrico, balões coloridos, bandeira do movimento Ipê Rosa (arco-íris) e muita animação do público. (DIÁRIO DA MANHÃ, 30/06/2003, p. 6).
O Popular, em local de destaque da primeira página na edição de 30 de junho de 2003, noticiava Parada Pede Inclusão Social, ressaltando a irreverência dos participantes com uma foto colorida de drag queens no centro desta primeira página. Já a reportagem completa tinha como título Gays Querem Punição Para Quem os Discrimina, mencionando-se a ocupação da rua pelos manifestantes que pediam "aprovação de projetos a favor da parceria civil e contra a discriminação". Advertia-se que o evento foi intitulado de $1^{\text {a }}$ Parada Unificada em virtude da ação conjunta do Ipê Rosa e da AGLT (Associação de Gays, Lésbicas e Travestis), sendo antecedido por extensa agenda de eventos, que perduraram por 15 dias. Informavam-se ainda os custos da comemoração (20 mil reais custeados pela Prefeitura, Coordenação Nacional de AIDS e UNESCO), criticando-se a ausência dos políticos locais, tanto da esfera estadual, quanto da municipal. Um dos entrevistados pelo O Popular, identificado como Júlio, de 68 anos de idade, asseverava a importância da parada: “...As paradas são maravilhosas porque ajudam a acabar com o preconceito" (30/6/2003, p. 5).

Espacialmente, o desfile de 2003 confirmava os vetores principais de territorialidades que se verificariam nas edições subsequentes determinados pela existência dos trios elétricos (quatro trios, de acordo com O Popular), além de a música aí tocada (eletromusic, dancemusic, housemusic) traduzir 'uma cultura gay' para os paradeiros e delimitar o território ocupado pela festa, no qual as performances corporais ritualísticas são fundamentais. Cabem aqui as ressalvas de Sack de que "a territorialidade pode ser afirmada de inúmeras maneiras, incluindo descrições de trabalho (...), direitos legais de terras, força bruta ou poder, normas culturais e proibições sobre o uso de áreas e 
formas sutis de comunicação, como postura do corpo" (2011, p. 78 - grifos nossos).

A ida da Parada para as ruas com trânsito de veículos e percorrendo suas avenidas principais (Paranaíba, Tocantins e Araguaia constitutivas da área conhecida por "manto de Nossa Senhora" no imaginário local), que são interrompidas para a passagem dos trios elétricos, deu-lhe maior visibilidade. A bandeira do arco-íris, em sua exibição pública, é tida como um dos principais símbolos da festa de acordo com as entrevistas que fizemos, em detrimento da cor rosa, mais sensível no cenário das primeiras manifestações.

Em 2004, a parada, realizada em 27 de junho, atrairia 3 mil participantes, segundo a polícia militar e O Popular; ou 4 mil de acordo com o Diário da Manhã, ou ainda 10 mil pessoas segundo os organizadores. $\mathrm{Na}$ reportagem de O Popular (28/6/2004, p. 7), advertia-se: "A manifestação está crescendo foram mil manifestantes a mais do que no ano passado - e ramificando seu leque político". O desfile seguiu pelas Avenidas Paranaíba, Goiás e Araguaia, despertando a atenção de transeuntes. Interessante neste evento foi a presença de dois peões cavaleiros em sua abertura (um com a bandeira do arcoíris e outro com a do Brasil) e a participação do GHOS (Grupo de Homossexuais Surdos), esboçando as várias microterritorialidades que começariam a se desenhar com o desfile circulando pelas ruas. O Popular estampava em sua primeira página, na porção inferior, uma foto destacando a bandeira do arco-íris. Aliás, nesta parada, as cores do arco-íris predominavam na decoração dos trios (oito no total, segundo O Popular), acessórios e roupas, sendo este aspecto ritualísticoterritorial recorrente nas edições posteriores.

Neste ano, no dia 26 de Junho, houve em Goiânia uma marcha para Jesus, reunindo cerca de 20 mil evangélicos, da qual participaram os então candidatos a prefeito
Iris Rezende e Sandes Júnior (DIÁRIO DA MANHÃ, 27/06/2004), ausentes na parada Gay, que comumente só atrai pouquíssimos candidatos ou ocupantes de cargo do legislativo, revelando um descaso dos pretendentes a cargo no executivo em Goiás com as reivindicações das minorias LGBTs. Um leitor do jornal Diário da Manhã, enviou por e-mail o seguinte comentário acerca da marcha:

Assisti à Marcha para Jesus com curiosidade e respeito. Impossível, contudo, não se sentir agredido pelas palavras de ordem e atitude dos participantes da mesma. Deixando para trás uma Praça Cívica coalhada de lixo, desceu a Araguaia uma multidão que, se só pela música, poderia ser a mesma da Parada Gay. Axé, rock e pop no último volume, igualzinho a outras paradas da vida! (DIÁRIO DA MANHÃ, 27/06/2004, p. 4).

De outro modo, Marcha Para Jesus e Parada Gay usam o mesmo apelo cultural dos trios elétricos e som pop para atrair o público, configurando uma relação de poder e produzindo um "território instável" como o define Souza (1995) ao abordar a relação entre território, poder e cultura.

Já em 2005 os eventos se estenderam de 5 a 14 de junho, promovendo-se a parada no dia 12 e havendo, entre outras atividades, um beijaço apoiado pelo grupo Colcha de Retalhos no centro de convivência da FACOMB/UFG, no dia 10 de junho, provavelmente em função da proximidade do dia dos namorados. A principal entidade promotora ainda é a Associação Ipê Rosa e estimou-se a participação de 20 mil pessoas. No dia 12 de junho, o jornal Diário da Manhã publicava uma matéria em que divulgava a existência de 10 trios elétricos no evento, 
destacando ainda o tema da parada: "Direitos iguais: nem mais, nem menos". Anunciava-se também a ocorrência de paradas nas seguintes cidades goianas: no mês de julho em Caldas Novas e Anápolis, e no mês de agosto em Quirinópolis. Paralelamente, divulgavam-se as atividades que antecederam a parada como as oficinas, palestras e mostras culturais (DIÁRIO DA MANHÃ, 12/06/2005).

No dia seguinte, em primeira página, noticiava-se que 20 mil pessoas compareceram ao evento, estampando-se esta manchete com foto da multidão em deslocamento segurando a bandeira do arcoíris. No caderno cidades, a reportagem sobre a parada destacava a participação de caravanas de Brasília e cidades do interior do Estado (Caldas Novas, Anápolis, Quirinópolis e Inhumas), bem como a tônica politizada da festa. Informava-se ainda que a parada de Goiânia "fica com o terceiro lugar em nível de aglomeração de público, perdendo apenas para a capital carioca e São Paulo" (DIÁRIO DA MANHÃ, 13/06/2005, p. 5). O Popular também trouxe a chamada da matéria enfocando a parada em sua primeira página, na qual se mencionava que sua organização partiu do Fórum LGBT de Goiás, que agregava seis entidades da capital e cinco do interior. O jornal, nas entrelinhas, traduzia as microterritorialidades do evento, já considerado a maior parada do CentroOeste: "Jovens vestidos de preto, em estilo dark ou heavy metal, outros com gorros com as cores da bandeira da Jamaica (...), fãs de reggae, marcavam presença ao lado de pais com crianças, curiosos, travestis, casais gays e heterossexuais" (O POPULAR,13/6/2005, p. 5).

No ano de 2006, aos 26 de junho, o Diário da Manhã divulgava que haveria 8 paradas no Estado de Goiás e a primeira marcada era a de Goiânia, no dia 2 de julho. No dia agendado, 2 de julho, em primeira página, o
Diário da Manhã noticiava $\mathrm{O}$ Poder Econômico dos Gays, reportagem que ocupou as páginas 10 e 11 deste veículo de comunicação abordando o pink-money, na qual notava-se que a festa, maior parada do Centro-Oeste, atraía caravanas de outros estados (como Minas Gerais e Tocantins) que vinham de véspera para Goiânia, movimentando o setor hoteleiro, boates, restaurantes e outros serviços e comércio. Nesta mesma edição, na página 5 , havia uma matéria específica sobre a parada, ressaltando as polêmicas que envolveram esta edição do evento, quais sejam: com a prefeitura municipal (pela falta de apoio na infraestrutura e na organização) e com o cantor sertanejo Leonardo (por supostas declarações homofóbicas no programa Domingão do Faustão). Já $\mathrm{O}$ Popular (3/7/2006, p. 8) abordou o crescimento da parada, cujo público foi estimado em $30 \mathrm{mil}$ pessoas, entre as quais estavam Luiz Mott e Rita Cadillac na qualidade de homenageados pelos organizadores, e também o protesto contra o cantor Leonardo.

No ano seguinte, as celebrações da Semana da Diversidade Cultural de Goiânia foram planejadas para o período de 2 a 9 de setembro, com a parada no último dia. Entretanto disputas políticas no movimento LGBT goianiense, além de uma greve no Ministério da Cultura motivaram o adiamento para o dia 28 de outubro, num evento que reuniu 50 mil participantes, de acordo com notícias da época (http://www.athosgls.com.br,

http://www.aids.gov.br/noticia). No dia do evento, $\mathrm{O}$ Popular publicou uma nota, na página 6 , expondo os objetivos da parada naquele ano, quem eram seus organizadores, e local e horário de concentração (portão central do Parque Mutirama, às 12 horas). $\mathrm{O}$ Jornal Diário da Manhã atentava que "a $11^{\mathrm{a}}$ edição do evento teve participação de simpatizantes e famílias inteiras, mas ainda 
com receio", havendo chamada na capa da edição do dia 29/10/2007 para a matéria. A reportagem trazia entrevistas com alguns ambulantes, que comercializavam seus produtos na festa; com a transformista Rayka Radã, que afirmava vir de São Paulo para participar desta parada tradicional no cenário Gay; com representante de uma caravana de Brasília composta por 54 pessoas; com os organizadores, que salientavam o apoio obtido pelo poder público naquela edição; entre outros atores. O Popular também estampou na capa, em lugar central, foto da parada e a reportagem acentuava a luta pelo fim do racismo, do machismo e da homofobia, particularmente pela aprovação da PLC 122/2006. Mencionam-se na matéria as disputas políticas na organização do evento e o racha ocorrido, a existência de dez trios elétricos e, novamente, a diversidade de participantes no desfile.

Em 2008, a parada foi realizada aos 21 de setembro, ocorrendo na concentração uma cerimônia de casamento gay como manifesto de desejo por direitos iguais (ou seria de normatividades, pois a cerimônia reproduziu pari passu ritualisticamente os casamentos 'convencionais'). $\mathrm{Na}$ véspera da parada, houve uma passeata pelas ruas da cidade solicitando a libertação do sargento Laci Araújo, ato comandado pelo seu companheiro Fernando Alcântara, que esteve presente à parada, e lideranças LGBTs de Goiânia. A edição do Diário da Manhã do dia 22 de setembro informou que participaram 80 mil pessoas, trazendo na primeira página uma foto dos noivos com seu "buquê de camisinhas". A celebração coube ao pastor Patrick Thiago Bomfim, de uma Igreja evangélica de Brasília. Já O Popular divulgou a participação de 20 mil pessoas, que se concentraram no Bosque Botafogo. O tema da parada "Nós Também Votamos! Pela garantia dos direitos" era igualmente destacado naquele ano eleitoral, seguindo-se do comentário: "Não por acaso (...) eram muitas as bandeirinhas, cartazes, santinhos e carros de som de postulantes aos cargos de vereador e prefeito, dos mais variados partidos políticos, durante a concentração" (O POPULAR, 22/9/2008, p. 4). Vejam que mudança, comparativamente ao passado recente, quando pleiteantes ou ocupantes de cargos no executivo e no legislativo ignoravam e/ou 'recusavam' convites dos organizadores.

No ano seguinte, a parada voltou ocorrer nas proximidades do feriado de 7 de setembro, mais especificamente, no dia 6, atraindo 7 mil participantes de acordo com a Polícia Militar, conforme publicado no Diário da Manhã e em O Popular. A redução de público, comparativamente ao ano anterior, foi motivada pela Gripe $\mathrm{A}$, de acordo com reportagens publicadas no dia 8 de setembro, fazendo com que os policiais responsáveis pela segurança do evento usassem máscaras descartáveis e estivessem apreensivos, conforme divulgou O Popular. Nas matérias advertia-se sobre a ausência de banheiros químicos na concentração do evento, pois a solicitação feita a Sedem referente a estes equipamentos não foi atendida. Nesta parada notou-se franca truculência da polícia ao final do evento, expulsando os participantes com golpes de cassetete e ameaças de atropelamento com suas viaturas, numa ostentação repressiva maior que aquela ocorrida no primeiro evento. Isto confirma as observações de Souza (2009, p. 67) acerca dos ativismos sociais, cujas práticas espaciais são ações de territorialização que "se concretizam em uma escala temporal curta ou de curtíssima duração, e são sempre marcadas, como é óbvio, pela instabilidade e às vezes pelo confronto violento com o estado".

Em 2010, a parada se despediria temporariamente das proximidades do Bosque Botafogo como área de concentração 
e dispersão. Interessante neste ano foi $o$ contrato de locação dos trios sob a responsabilidade da Igreja IRIS, que se intitula como uma igreja inclusiva, estando esta igreja entre as entidades organizadoras nos anos de 2009, 2010 e 2011. Aliás, a presença desta 'igreja' revelou ranços de normatividades (e homonacionalismo?), conforme destaca Maia (2011, p. 254):

o "lado religioso" já foi comandado pelo pastor da Igreja IRIS, que subiu ao palco para falar sobre religião e diversidade de orientação sexual e respeito aos direitos LGBTs. O interessante foi que, no momento em que este falava, uma travesti que estava em frente ao palco retirou a sua blusa e expôs os seios. O pastor, ao ver a cena proferiu: "- Travesti, coloque a sua blusa! Nada de peito de fora! A mídia está aqui e nós queremos mostrar que esta é uma festa de família! E a mídia só mostra isso!". Mais interessante ainda que as palavras ordeiras do pastor foi a reação do público que estava diante do palco assistindo à sua fala (ou seja, aquela minoria que não estava próxima dos trios ou dos vendedores de comidas e bebidas), que começou a aplaudi-lo, manifestando censura à travesti. Uma participante [travesti], mais exaltada, inclusive gritou: "- Se veste, veado!".

De acordo com reportagem do Diário da Manhã, estimaram-se $10 \mathrm{mil}$ pessoas presentes na festa (redução quiçá decorrente da truculência policial do ano anterior, espantando caravanas de turistas, tanto quanto o público local), mas $\mathrm{O}$ Popular (6/9/2010, p. 2) divulgou a presença de mais de 70 mil participantes, entre os quais estavam candidatos ao legislativo pedindo votos, vendedores e ambulantes. $\mathrm{Na}$ véspera do evento, 4 de setembro, O Popular, publicava uma carta de leitora na coluna 'opinião' em que ela destacava o apelo político naquela edição, cujo lema foi "nosso voto, nossa força, por um Brasil sem homofobia". A leitora ainda ressaltava a importância da parada na busca da garantia dos mesmos direitos civis dos heterossexuais para a parcela da população LGBT e comentava: "Enfim, a festa colorida faz parte da luta por direitos e por uma sociedade justa e igualitária" (O POPULAR, 4/9/2010, p. 7). Ainda que esta luta por uma sociedade justa e igualitária seja coberta pela bandeira LGBT, a parada traduz a própria discriminação de 'minorias contra minorias' neste segmento e as suas normatividades. Em Goiânia, presenciamos nas edições de 2010, 2011 e 2012 cartazes contra a passivofobia, transfobia, lesbofobia, preconceito aos gays idosos, etc.; muitas vezes praticados entre os próprios gays passivos, e mesmo ativos, contra os passivos, lésbicas ladies contra as chamadas caminheiras, jovens gays contra os denominados de 'cacuras' (idosos, ou seja, entre os gays, já se considera 'cacura' - idoso - os que estão na faixa acima dos 50 anos), etc. (figuras 2 e 3 ).

Nas edições de 2011 e 2012, em virtude de obras de intervenção no Bosque Botafogo, o local de concentração e dispersão também foi alterado. Em 2011, destinou-se a Praça Cívica para este fim e, em 2012, o Mercado Aberto de Goiânia, na Rua Paranaíba; porém mantendo-se o circuito pelo "manto de Nossa Senhora". As datas foram 4 de setembro, em 2011, com público estimado em 50 mil participantes, e 9 de setembro, em 2012, com a concorrência de 100 mil pessoas.

Note-se que no ano de 2011, O Popular, no dia da festa, noticiava as mudanças no trânsito e as preocupações da Agência Municipal de Trânsito e Transportes de não interrompê-lo completamente; ou seja, a 


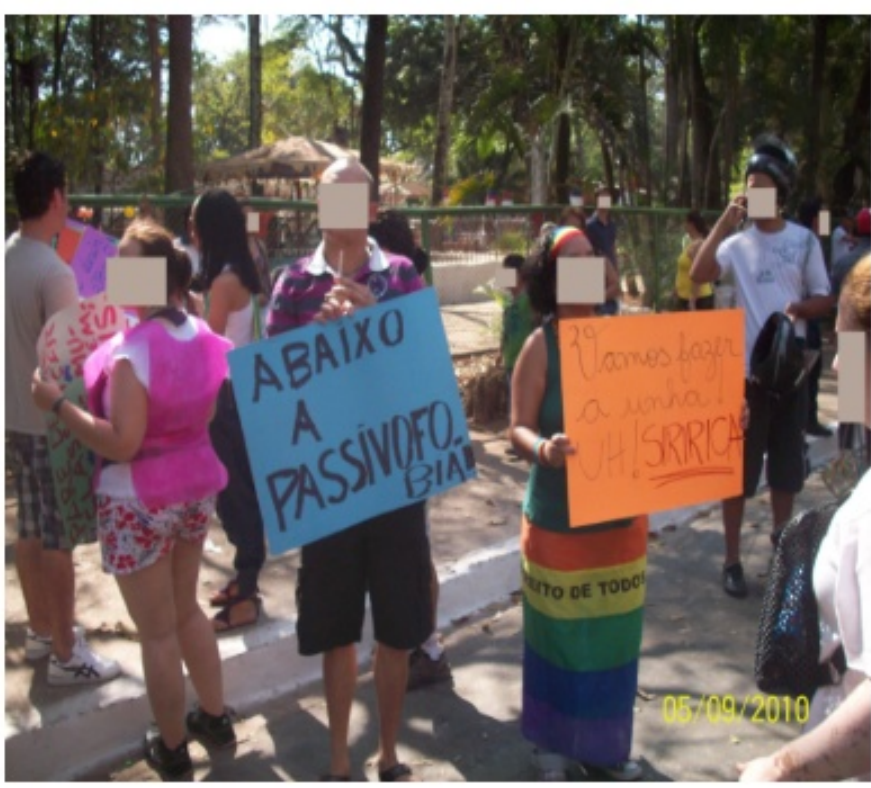

Figura 2: cartaz contra "passivofobia"

Fonte: o autor, 2010 (pesquisa de campo)

dinâmica de circulação urbana da cidade era efetivamente outra durante a parada nesta nova década. Em relação às notícias posteriores, o Diário da Manhã (5/9/2011) ressaltou a pouca participação de políticos e ainda o desejo dos participantes de que a Polícia Militar fizesse a segurança do evento, mas não agredisse os participantes, como ocorreu no ano anterior. Já o Popular (5/9/2011) sublinhou o cenário novo de concentração e dispersão (Praça Cívica), as mudanças na paisagem do Centro com as cores do arco-íris e a música eletrônica, a forte presença de jovens, o "encanto das drags" e os atos políticos.

As entrevistas que realizamos nos anos de 2010 e 2011 nos indicaram que, embora a maioria dos participantes seja proveniente da periferia de Goiânia, a parada atraía também participantes de diversas cidades do entorno. Assim, entre os que se declararam homossexuais/bissexuais/outro, tivemos, em dados brutos: 43 residentes em Goiânia, 6 em Brasília, 4 em Anápolis, 4 em Aparecida de Goiânia, 2 em Trindade e 12 em outras

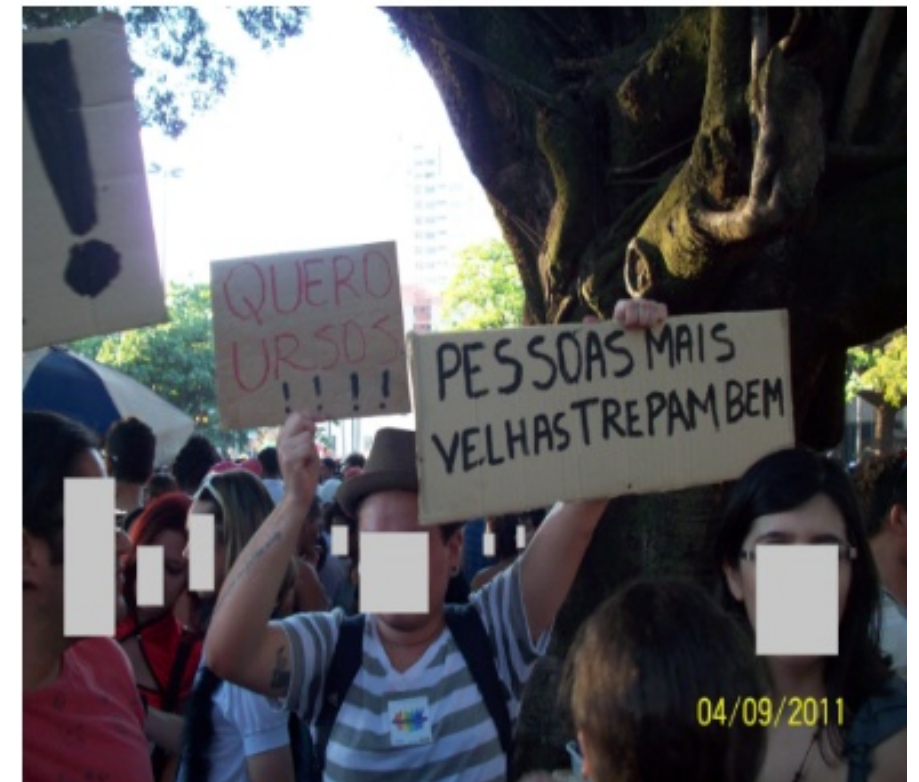

Figura 3: cartaz contra preconceitos aos gays/lésbicas idosos e idosas

Fonte: o autor, 2011 (pesquisa de campo)

cidades, sendo um para cada uma destas: Senador Canedo, Caldas Novas, Terezópolis, Guapó, Turvânia, Rio Verde, Ouro Verde, Formosa, Campinas, São Paulo, Uberlândia e Cuiabá. Já entre os que se declararam heterossexuais, as cidades de residência citadas foram (em dados brutos): $15 \mathrm{em}$ Goiânia, 1 em Brasília, 1 em São Paulo e 1 em Londres. Os que não revelaram a sua orientação sexual eram das seguintes cidades (em dados brutos): Goiânia (1) e Ilhéus (1). Note-se que, na maioria dos casos dos participantes provenientes de outras cidades no eixo Goiânia-Brasília, o deslocamento para Goiânia foi intencional a fim de participar da parada, às vezes em caravanas organizadas e/ou com grupos de amigos. Mas havia pessoas que estavam na cidade em função do feriado para visitar parentes e aproveitaram para "ir à parada". Houve também aqueles/aquelas que expressaram planejamento prévio visando conciliar as duas coisas: visitar a família no "feriado da parada". Esta "ida à parada" produz em qualquer caso uma territorialidade temporária 
onde imperam, como destaca Parkin (1992, p. 18), "idioms of passage, movement, including exchange, journey, axis, concentrism, and up-and-down directions". Sobre a mudança do local de concentração/dispersão para a Praça Cívica, as opiniões foram variadas, com alguns/algumas se manifestando a favor em virtude da centralidade, já outros preferiam o "bosque" por considera-lo "mais tradicional e ambientalmente mais agradável".

A proximidade da parada com o feriado de 7 de setembro e seu distanciamento do Dia Orgulho Gay talvez estejam contribuindo para a emergência no imaginário coletivo goianiense de uma nova representação simbólica do ritual, de modo que, entre os/as entrevistados/as nos anos de $2010 \quad$ (50 participantes) e 2011 (42 participantes), quando perguntados/as sobre o movimento que levou à organização de Paradas LGBTs no mundo, apenas 2 responderam, de modo genérico, "assassinato nos Estados Unidos", 1 não respondeu e os 49 outros/as não souberam da referência deste evento com o 'mito fundador de Stonewall'. No deslocamento ritualístico para ir à parada, visões de mundo relacionadas à realidade LGBT (de si e dos outros) são grafadas no palimpsesto do 'mito de Stonewall', no qual alguns/mas participantes aproveitam para reescrever a própria história, fazendo da parada um rito de passagem. Acerca disso, houve quem declarasse que "se assumiu na primeira parada", ou ainda "aproveitou o fato participar pela primeira vez para contar à família", sendo isto também mencionado por outros autores, como Blidon (2009) e Hauswirth (2006). Entretanto, mesmo que a parada atraia turistas para a cidade, o empresariado local e o poder público prestam pouca atenção nisto, o que se reflete no parco apoio que os organizadores têm para promover o evento, como expressaram em entrevistas.
No ano de 2012 a parada foi realizada no dia 9 de setembro e houve nova mudança no local de concentração e dispersão: $O$ Mercado Aberto, situado na Avenida Paranaíba. Cerca de 100 mil pessoas estiveram presentes ao evento, que foi encerrado com um baile popular neste local (Mercado Aberto). Conforme notado em reportagem de O Popular (10/9/2012), no dia 7 de setembro, quatro travestis foram mortas na região metropolitana de Goiana e, nas entrevistas que fizemos, percebemos a concorrência de muitas famílias que foram à parada pela primeira vez para protestarem contra estes crimes e ainda pela concentração ter ocorrido num lugar mais centralizado. A morte das travestis alinhavou os discursos da comissão organizadora da parada em prol da aprovação da PLC 122 (DIÁRIO DA MANHÃ 10/9/2012, p. 5, O POPULAR 10/9/2012, p. 8).

Em 2013, a $17^{\text {a }}$ parada foi realizada no dia 15 de setembro, ocorrendo a concentração e dispersão próximas ao Bosque Botafogo. Nesta edição, tendo como tema "PLC 122 e Estado Laico Já!", estimou-se a concorrência de público em mais de 150 mil pessoas, de acordo com os organizadores, ou 30.000, segundo a Polícia Militar (O POPULAR, 16/9/2013, p. 8, DIÁRIO DA MANHÃ, 16/9/2013, p. 6). O Popular mais uma vez ressaltou a participação de caravanas na parada, o que nos leva a conjecturar sua afirmação como atração turística da cidade na qualidade de evento voltado ao segmento LGBT: "Pessoas de Goiânia, de outras cidades e até de outros Estados, cujos grupos e associações em prol dos direitos homossexuais organizaram caravanas, vieram participar da parada" (O POPULAR, 16/9/2013, p. 8). Ainda conforme O Popular, "essa foi a primeira vez que a Prefeitura de Goiânia participou ativamente da Parada do Orgulho Gay. Esta parceria foi articulada pela Assessoria 
Especial Para Assuntos da Diversidade Sexual" (O Popular, 16/9/2013, p. 8). É provável que as polêmicas provocadas pelo pastor-deputado Marco Feliciano na Comissão de Direitos Humanos da Câmara de Deputados tenham acentuado os discursos a favor do Estado laico.

\section{Together, We will start like new}

Ao terminarmos este trabalho, esperamos ter contribuído para demonstrar como a parada goianiense foi se constituindo como festa e, em efeito, um fato social total. Embora o foco principal tenha sido as mudanças nas territorialidades e sua turistificação, aproveitou-se para debater sobre como o arco-íris festivo é pintado com tons de desconstruções e normatividades, tradições e rupturas, identidades e diferenças. Notou-se ainda que manifestações de homonacionalismo fazem-se presentes, desvelando flertes com ideologias neoliberais, ainda que disfarçadas sob uma moralidade judaico-cristã conservadora. O caráter mesmo de fato social total da parada como festa e esses tons dados ao arco-íris festivo a levou saltar de 8 participantes em sua primeira edição, no ano de 1996, para mais de 100 mil em 2013, ampliando a gama de organizadores. Entretanto, mesmo com as pinceladas de normatividades, homonacionalismos e conservadorismo este arco-íris aponta para a existência um pote de ouro a ser buscado, repleto de respeito às diversidades.

* Texto parcialmente baseado na comunicação livre intitulada "It's Raining Men: Deslocamentos Ritualísticos e Territorialidades Temporárias na Parada LGBT Goianiense", apresentada no Tercer Congreso Latinoamericano de Antropología ALA 2012. Título e subtítulos referenciados na música Go West, composta por Henri Belolo, Jacques Morali, Victor Willis e gravada pelo grupo Village People.

1 Este conflito pode ser verificado nos seguintes endereços eletrônicos: http://www.streetdirectory.com/etoday/london-newyork-miami-claepw.html, http://gayactivist.overblog.com/article-yesterdays-75678803.html, http://gayactivist.over-blog.com/, http://www.orbispictus.co.uk/gallery_507909.html..

2 Documento disponível em http://acervo.cidarq.ufg.br/index.php/parada-de1999;isad

3 A Associação Ipê Rosa era definida como uma Organização Não Governamental, sem fins lucrativos, com base comunitária e fundada em 1 de setembro de 1995, objetivando defender os direitos humanos daqueles identificados como LGBT, a liberdade da expressão sexual, a diversidade sexual e combater a homofobia, atuando ainda na prevenção de DST e AIDS (http://acervo.cidarq.ufg.br/index.php/parada-de1999;isad).

$4 \quad$ Consulte-se

acervo.cidarq.ufg.br/uploads/3/7/37300/ADV-MOBI3-6.pdf.

\section{Referências}

$1^{a}$ PARADA Unificada do Orgulho GLBT de Goiânia. Disponível em: $<$ acervo.cidarq.ufg.br/uploads/3/7/37300/AD V-MOBI-3-6.pdf $>$. Acesso em 26 de Novembro de 2013.

BLIDON, Marianne. La Gay Pride entre subversion et banalisation. Espace populations sociétés [En ligne]. p. 1 - 15, 2009/2. Disponível em: $<$ http://eps.revues.org/index3727.html $>$.

Acesso em 10 de Julho de 2013.

BORGES, Laryssa. 'A união homossexual não é normal', diz candidato à presidência da Comissão de Direitos Humanos da Câmara. Revista Veja. Disponível em: 
$<$ http://veja.abril.com.br/noticia/brasil/auniao-homossexual-nao-e-normal-dizcandidato-a-presidencia-da-comissao-dedireitos-humanos-da-camara>. Acesso em 10 de Julho de 2013.

BRANSON, Lindsay. Gay Liberation Front. Outhistory.org. (s.d.) Disponível em: < http://www.outhistory.org/wiki/Gay_Liberati on_Front $>$. Acesso em 10 de Dezembro de 2012.

CENTRO de Documentação e Arquivo (Cidarq) da UFG. [Fotos e documentos diversos]. Disponível em $<$ http://acervo.cidarq.ufg.br/index.php/gpkcp; isad $>$.

CONDEIXA, Ana Claudia. Ruas e bancas coloridas: os discursos da imprensa sobre as identidades homossexuais nas Paradas LGBT do Rio de Janeiro e de São Paulo. Revista ComUnigranrio. p. 1 - 19, 2009. Disponível em:

$<$ http://publicacoes.unigranrio.edu.br/index.p $\mathrm{hp} /$ comunigranrio/issue/view/54>. Acesso em 11 de Dezembro de 2012.

DI MÉO, Guy (Org.). La géographie em fêtes. Paris: Ophrys, 2001.

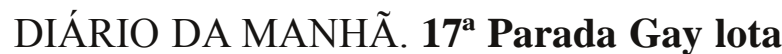
o Centro de Goiânia com Milhares de Pessoas. 16/9/2013, p. 6 (Cidades).

DIÁRIO DA MANHÃ. 80 Mil celebram orgulho Gay. 22/9/2008, p. 17 (Cidades).

DIÁRIO DA MANHÃ. A rua da diversidade. 29/6/2001, p. 9-a.

DIÁRIO DA MANHÃ. Cor-de-Rosa. 27/6/1998, p. 8 (Revista).

DIÁRIO DA MANHÃ. Desfile Polêmico.
02/7/2006, p. 5 (Cidades).

DIÁRIO DA MANHÃ. Economia Segmentada: Negócios - Parada Gay movimenta comércio em Goiânia e desperta empresários para este novo nicho. 02/7/2006, p. 10-11 (Economia).

DIÁRIO DA MANHÃ. Excluídos fazem protesto em Goiânia no Dia da Diversidade. 8/6/1998, p. 3 (Local).

DIÁRIO DA MANHÃ. Gays comemoram Dia do Orgulho. 29/6/1998, p. 3 (Local).

DIÁRIO DA MANHÃ. Gays fazem 8 passeatas em Goiás. 26/6/2006, p. 3 (Cidades).

DIÁRIO DA MANHÃ. Goiânia elege sua Miss Travesti. 27/6/1998, p. 4 (Local).

DIÁRIO DA MANHÃ. Homossexuais ganham bandeira. 28/06/2002, p. 3 (Cidades).

DIÁRIO DA MANHÃ. Homossexualismo. 29/6/2003, p. 2 (Cidades).

DIÁRIO DA MANHÃ. Manifestação reúne 15 mil Gays em São Paulo. 28/6/1999, p. 3 (Nacional).

DIÁRIO DA MANHÃ. Manifestação reúne três mil pessoas. $30 / 6 / 2003$, p. 6 (Cidades).

DIÁRIO DA MANHÃ. Marcha por Jesus. 27/6/2004, p. 8 (Cidades).

DIÁRIO DA MANHÃ. Marcha. 27/6/2004, p. 4 (Opinião do leitor).

DIÁRIO DA MANHÃ. Mostra de Cinema Gay. 29/6/1997, p.3. 
DIÁRIO DA MANHÃ. O dia do orgulho gay - o que comemorar e o que lamentar. 28/6/2001, p. 11-a.

DIÁRIO DA MANHÃ. Parada do Orgulho Gay Reúne 100 mil na capital. 10/9/2012, p. 5 (Cidades).

DIÁRIO DA MANHÃ. Parada Gay em Goiânia. 12/6/2005, p. 4 (Cidades).

DIÁRIO DA MANHÃ. Parada Gay reúne 100 mil na capital. $10 / 09 / 2012$, p. 6 (Cidades).

DIÁRIO DA MANHÃ. Parada Gay reúne 20 mil em Goiânia. 13/6/2005, p. 5 (Cidades).

DIÁRIO DA MANHÃ. Parada Gay reúne 50 mil. 29/10/2007, p. 15 (Cidades).

DIÁRIO DA MANHÃ. Parada Gay reúne 50 mil no Centro. 05/09/2011, p. 5 (Cidades).

DIÁRIO DA MANHÃ. Parada Gay reúne 50 mil no Centro. 07/09/2009, p. 2 (Cidades)

DIÁRIO DA MANHÃ. Parada LGBT reúne mais de $\mathbf{1 0}$ mi. 06/09/2010, p. 3 (Cidades).

DIÁRIO DA MANHÃ. Parada LGBT reúne mais de $\mathbf{1 0}$ mil. 06/09/2010, p. 3 (Cidades).

DIÁRIO DA MANHÃ. Polícia Reprime Homossexuais. 29/6/1996, p. 2.

FORTUNA, Carlos. (Micro)territorialidades: metáfora dissidente do social. Terr@Plural, Ponta Grossa, v. 6, n.2, p. 199 - 214, 2012.
GOETZMANN, Stéphanie. L'homosexualité: du secret à la fierté. Sociétés [En ligne], v. 3, n. 73, p. $71-78,2001$.

GRAU, Begoña Enguix. Identidades inteligibles y cuerpos disidentes en la España contemporánea. Revista Latinoamericana de Estudios sobre Cuerpos. Emociones y Sociedad. v. 2, n. 2, p. 49 - 61, 2010.

GRAU, Begoña Enguix. Sexualidad e identidades. Identidades homosexuales. Gazeta de Antropología, n. 16, p. 1 - 8, 2000 .

HAUSWIRTH, Kevin. Keeping our pride. The Advocate, v. 20, p. 38, 2006.

KERTZER, David. Rituais políticos e a transformação do Partido Comunista Italiano. Horizontes Antropológicos, v. 7, n. 15, p. 15 - 36, 2001.

LEROY, Stéphane. «Bats-toi ma soeur». Appropriation de l'espace public urbain et contestation de la norme par les homosexuels. Métropoles [En ligne], n. 8, p. $1-25,2010$.

MAIA, Carlos Eduardo Santos. Cidade e Festa: os excessos nas paradas LGBTs reflexões a partir da realidade goianiense. Revista Cidades, v. 1, n. 1, p. 233 - 294, 2011.

MAIA, Carlos Eduardo Santos. Festividade e Territorialidades na Parada LGBT Goianiense.Terr@ Plural, v. 6, n. 2, p. 273 - 288, 2012 .

MAIA, Carlos Eduardo Santos. Ritual e emoção nas interações espaciais repensando o espaço sagrado nas festas populares de romarias e folguedos (notas introdutórias). In: ROSENDAHL, Zeny. 
(Org.). Trilhas do Sagrado. Rio de Janeiro: Eduerj, 2010b, p. 87 - 111.

MAIA, Carlos Eduardo Santos. Soltando o verbo: ratos e urubus, diretamente o povo escolhia o presidente. Textos escolhidos de cultura e arte populares. v. 7, n. 2, p. 109 125, 2010a.

NASCIMENTO, Cláudio. Da Escuridão ao Arco-íris. (s.d.). Disponível em: $<$ http://www.rj.gov.br/web/seasdh/exibeconte udo? article-id=987634>. Acesso em 10 de Julho de 2013.

O POPULA. Homossexuais Comemoram Hoje Dia da Diversidade. 28/6/1999, p. 14.

O POPULAR. Cores do Arco-Íris Pintam o Centro. 5/9/2011, p. 4 (Cidades).

O POPULAR. Gays querem punição para quem os discrimina. 30/6/2003, p. 5 (Cidades).

O POPULAR. Goiânia Trânsito muda para a Parada Gay. 26/6/2000, p. 15.

O POPULAR. Goianos Lideram Parada Gay. 4/9/2011, p. 5.

O POPULAR. Gripe Suína Esvazia Parada Gay. 7/9/2009, p. 5 (Cidades).

O POPULAR. Homossexuais Comemoram Dia do Orgulho Gay. 28/6/1998, p. 13.

O POPULAR. Homossexuais Parada Gay de Goiânia Reúne 30 Mil. 3/7/2006, p. 8 (Cidades).

O POPULAR. Identificado Travesti Morto. 28/6/2000, p. 13.

O POPULAR. Luiz Mott Tira Gays
Históricos do Armário. 30/6/1999, Caderno 2, p. 2.

O POPUlAR. Manifestação Parada Gay Pede fim da Homofobia. 28/10/2007, p. 6 (cidades).

O POPULAR. Milhares na Rua Pela Diversidade. 29/10/2007, p. 2 (Cidades).

O POPUlAR. Mott, Luiz. Consciência Homossexual. 28/6/1998, p. 11 (Carta dos Leitores).

O POPULAR. Movimento GLS Comemora Dia de Orgulho Gay. 28/6/1996, p.2.

O POPULAR. ONU Adverte Para Catástrofe da AIDS e Brasil é Elogiado. 28/6/2000, p.4.

O POPULAR. Para Celebrar o Orgulho Gay. 28/6/2003, p.3 (Magazine).

O POPULAR. Parada do Orgulho Gay Reúne Milhares em Goiânia. 13/6/2005, p. 5 (Cidades).

O POPULAR. Parada Gay - Desfile Contra Homofobia Reúne 100 Mil Pessoas. 16/9/2013, p. 8 (Cidades).

O POPULAR. Parada Gay Clama por Respeito e Tolerância. $10 / 7 / 2012$, p. 8 (Cidades).

O POPULAR. Parada Gay Diz não à Homofobia. 06/09/2010, p. 2 (Cidades).

O POPULAR. Parada Gay Pede Direitos Iguais. 22/9/2008, p. 4 (Cidades).

O POPULAR. Parada Manifestação Gay Reúne 3 mil em Goiânia. 28/6/2004, p. 7 (Cidades). 
O POPULAR. Por um Brasil sem Homofobia. 4/9/2010, p. 7 (Opinião).

O POPULAR. Repressão Marca Dia do Orgulho Gay. 29/6/1996, p. 2.

PARADA Gay de Goiânia muda a data. Disponível em: $<$ http://www.athosgls.com.br/noticias visuali za.php? contcod=21117>. Acesso em 30 de Outubro de 2012.

PARADA GLBT de Goiânia sai com comando dividido em 2007. Disponível em: $<$ http://www.aids.gov.br/noticia/ate-o-ano-de2006-leo-mendes-coordenou-paradas-doorgulho-de-gays-lesbicas-bissexuais-e-tran. Acesso em 30/10/2012>.

PARKIN, David. Ritual as spatial direction and bodily division. In: COPPETT, Daniel de. Understanding rituals. London: Routledge, 1992, p. 11 - 25.

PESQUISA Revela Grau de Violência Contra Lésbicas. Diário da Manhã, 28/6/1999, p. 1 (Local).

PRADO, Patrick. Fêtes globales, fêtes locales. Autour d'Halloween. Ethnologie française, n. 1, p. $131-136,2000$.

PUAR, Jasbir. Rethinking Homonationalism. Int. J. Middle East Stud, v. 45, p. 336 - 339, 2013.

SACK, Robert David. O significado de territorialidade. In: DIAS, Leila Cristina; FERRARI, Maristela. Territorialidades Humanas e Redes Sociais. Florianópolis: Insular, 2011, p. 63 - 90.

SANTOS, Gustavo Gomes da Costa. Mobilizações homossexuais e Estado no Brasil: São Paulo (1978-2004). Rev. bras.
Ci. Soc. [online], v. 22, n. 63, p. 121 - 135, 2007.

SARGEANT, Fred. 1970: A First-Person Account of the First Gay Pride March: Remembering the March, a year after the Stonewall riots. The Village Voice News, $2010 . \quad$ Disponível em: $<\mathrm{http}$ ://www.villagevoice.com/2010-06-

22/news/1970-a-first-person-account-of-thefirst-gay-pride-march/>. Acesso em 10 de Julho de 2013.

SOUZA, Marcelo José Lopes de. 'Território' da divergência (e da confusão): em torno das imprecisas fronteiras de um conceito fundamental. In: SAQUET, Marcos; SPOSITO, Eliseu. Territórios e territorialidades: teorias, processos e conflitos. São Paulo: Expressão Popular, 2009 , p. $57-72$

SOUZA, Marcelo José Lopes de. O Território: sobre espaço e poder, autonomia e desenvolvimento. In: CASTRO, Iná Elias d; GOMES, Paulo Cesar da Costa; CORRÊA, Roberto Lobato. Geografia: conceitos e temas. Rio de Janeiro: Bertrand Brasil, 1995, p. $77-116$.

SPENCER, Colin. Histoire de l'Homosexualité - de l'Antiquité à nos jours. S.1.: Le Pré aux Clercs, 1998.

Recebido em 19 de março de 2014. Aceito em 25 de maio de 2014. 